\title{
REVIEW OF SYN-FLOODING ATTACK DETECTION MECHANISM
}

\author{
Mehdi Ebady Manna and Angela Amphawan \\ School of computing, University Utara Malaysia, Kedah, Malaysia \\ meh_man12@yahoo.com; angela@uum.edu.my
}

\begin{abstract}
Denial of Service (DoS) is a security threat which compromises the confidentiality of information stored in Local Area Networks (LANs) due to unauthorized access by spoofed IP addresses. SYN Flooding is a type of DoS which is harmful to network as the flooding of packets may delay other users from accessing the server and in severe cases, the server may need to be shut down, wasting valuable resources, especially in critical real-time services such as in e-commerce and the medical field. The objective of this paper is to review the state-of-the art of detection mechanisms for SYN flooding. The detection schemes for SYN Flooding attacks have been classified broadly into three categories - detection schemes based on the router data structure, detection schemes based on statistical analysis of the packet flow and detection schemes based on artificial intelligence. The advantages and disadvantages for various detection schemes under each category have been critically examined. The performance measures of the categories have also been compared.
\end{abstract}

\section{KEYWORD}

Network security, Denial of Service (DoS), SYN-Flooding

\section{INTRODUCTION}

Information has become an organization's most precious asset. Organizations have become increasingly dependent on information. The widespread use of e-commerce has increased the necessity of protecting the system to a very high extent[1]. Denial of Service (DoS) is a security threat which compromises the confidentiality of information stored in Local Area Networks (LANs) due to unauthorized access by spoofed IP addresses. DoS is harmful to LANs as the flooding of packets may delay other users from accessing the server and in severe cases, the server may need to be shut down, wasting valuable resources, especially in critical real-time services such as in e-commerce.

The term security refers to the protection of essential information against unauthorized access. There are many types of threats that violate the information that can be accessed by global network: theft and fraud, hackers, Denial of Service (DoS) and virus [2](see Table 1) below. In addition, it is difficult to make a global secure system for the entire network (i.e. the Internet). 
Table 1: Examples of Threats

\begin{tabular}{|l|c|c|c|c|c|}
\hline \multicolumn{1}{|c|}{ Threat } & $\begin{array}{c}\text { Theft and } \\
\text { Fraud }\end{array}$ & $\begin{array}{c}\text { Loss of } \\
\text { Confidential }\end{array}$ & $\begin{array}{c}\text { Loss of } \\
\text { Privacy }\end{array}$ & $\begin{array}{c}\text { Loss of } \\
\text { integrity }\end{array}$ & $\begin{array}{c}\text { Loss of } \\
\text { Availability }\end{array}$ \\
\hline $\begin{array}{l}\text { Using another person's } \\
\text { means of access }\end{array}$ & $\sqrt{ }$ & $\sqrt{ }$ & $\sqrt{ }$ & \\
\hline $\begin{array}{l}\text { Unauthorized amendment } \\
\text { or copying of data }\end{array}$ & $\sqrt{ }$ & & & $\sqrt{ }$ & $\sqrt{ }$ \\
\hline Program alteration & $\sqrt{ }$ & $\sqrt{ }$ & $\sqrt{ }$ & & \\
\hline Illegal entry by hacker & $\sqrt{ }$ & $\sqrt{ }$ & $\sqrt{ }$ & & $\sqrt{ }$ \\
\hline Blackmail & $\sqrt{ }$ & $\sqrt{ }$ & & $\sqrt{ }$ \\
\hline $\begin{array}{l}\text { Thefts of data, programs } \\
\text { and equipment }\end{array}$ & $\sqrt{ }$ & $\sqrt{ }$ & $\sqrt{ }$ & $\sqrt{ }$ & \\
\hline Inadequate staff training & & $\sqrt{ }$ & $\sqrt{ }$ & & \\
\hline $\begin{array}{l}\text { Viewing and disclosing } \\
\text { unauthorized data }\end{array}$ & $\sqrt{ }$ & & & $\sqrt{ }$ & $\sqrt{ }$ \\
\hline Introduction of virus & & & &
\end{tabular}

Any violation in security leading to loss of confidence and loss of privacy could lead to illegal action taken against an organization. On the other hand, loss of data integrity results in invalid or corrupted for information. Hence, losing any factor of these criteria would cause significant harm in business for the organization assets such as loss customer confidence, contract damages, regulatory fines and restrictions, or a reduction in market reputation. In the worst case, a failure to control or protect information could lead to significant financial losses or regulatory restrictions on the ability to conduct business.

\section{NETWORK THREATS}

A network threat is any form of security breach which is intended for access to protected information or corrupt it [3]. For example, "viewing and disclosing unauthorized data is a threat which may result in theft and fraud, loss of confidentially and loss of privacy for the company. In addition, the important activities are continuously running and users remain unaware of known vulnerabilities and the patches that address them. To this end, a useful security tool is to identify how a particular application advises users of the existence of security vulnerabilities and availability of patches to address them (by newsgroup posting, mailing list, corporate web site, etc.) [4]. Network threats may include any of the following:

a. Wiretapping: intercepting the communications by a passive or active way.

b. Impersonation: pretending to be someone (personnel) or something (process).

c. Hacking:breaking down the computer system security.

d. Virus, Trojans and worms, the definitions as below:

- A computer virus is a hidden program written to alter the way the computer operates. It attaches itself to a program or file enabling it to spread from one computer to another and causing infections as it is travels.

- Worms are a sub-class of virus in design and code written. It has the ability to spread from computer to computer, but unlike a virus, it has the capability to travel without any human action.

- Trojan is a program that appears to be useful software but will actually do damage once installed or run on computer. For example, Trojan horse.

e. Denial of Service Attacks (DoS). 


\section{The Concept of Denial of Service (DoS) Attack}

In order to understand previous forms of detection for Denial of Service (DoS) attacks, it is important to first understand the concept of DoS attacks. There are several types of DoS attacks. In this paper, the focus is on a type of DoScalled SYN-flooding. An attacker in SYN-flooding sends a succession of SYN request to a victim's system in an attempt to make a system unresponsive to legitimate traffic. The SYN-flooding attacks exploit the TCP's three-way handshake mechanism and its limitation in maintaining half-open connections. The SYNflooding attacks' abuse network resources and can bring about serious threats to the internet. On the other hand, the SYN-flooding attack is networks anomalies usually refer to the conditions when network operations diverge from the normal behavior [5]. Anomaly detection in a network is a very complex task for SYN-flooding attack, because it is dependent upon the nature of the data that is available for the analysis.

The SYN-flooding data can be classified into two major types: the first is network-based and the second is end-user-based [6], [7].

This attack can cause significant financial losses in the client/ server network, especially in ecommerce. When a server receives a SYN request, it returns a SYN/ACK packet to the client. Until the SYN/ACK packet is acknowledged by the client, the connection remains in a halfopen state for a period of up to the TCP connection timeout, which is typically set to 7.5 seconds during the SYN-flooding attacking time[8]. The half-open connection keeps the server in waiting state to be acknowledged by the client. However, the server has built in its system memory a backlog queue to maintain all half-open connections. Since this backlog queue is of finite size, once the backlog queue limit is reached to the maximum limited number, all connection requests will be dropped within SYN-flooding attack's time [9], [10].

\section{TYPES OF DENIAL OF SERVICE (DOS)}

Denial of Service (DoS) attack is a common threat from the user which disrupts a service on the network. It can be defined as any action or series of actions that prevent any part of a telecommunications system from functioning. A very common example is the SYN-flood attack, which is simply to send a large number of SYN packets and never acknowledge any of the replies and bombarding the service with such a large number of pointless requests that the serious users are unable to use it. See (Fig.1).

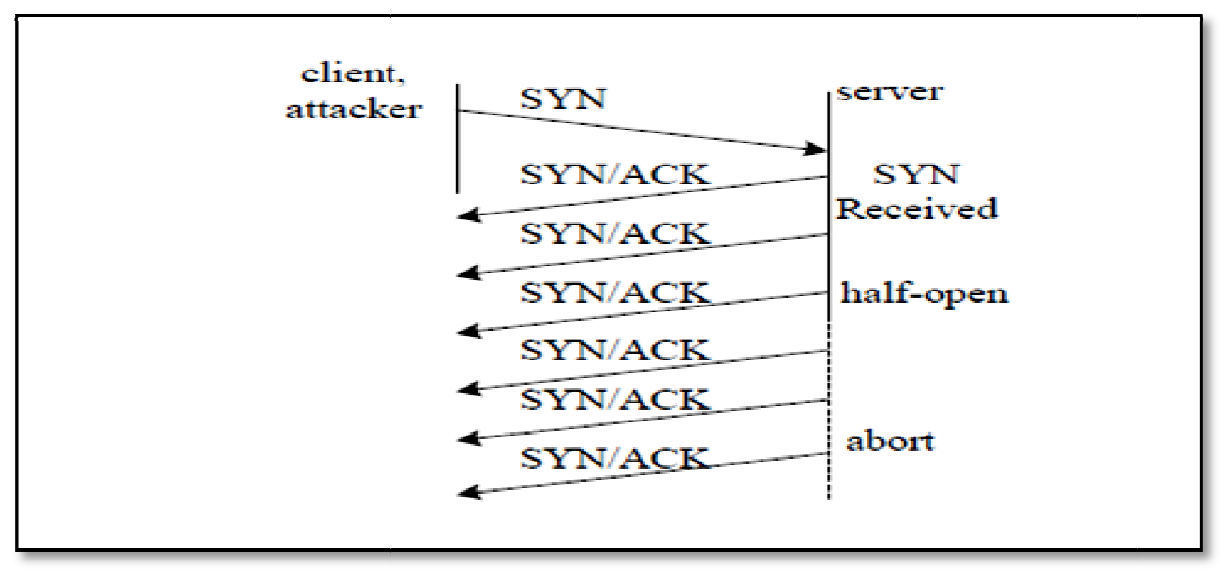

Figure 1. SYN-Flooding attack scenario 
Some other examples of DoS types include Ping Flood and Ping of Death which less on larger networks or websites because only one computer is being used to flood the victim's resources as below:

- $\quad$ Ping flood:It relies on the ICMP echo command, more popularly known as ping. It is the most basic of attacks, which used by network administrators to test connectivity between two computers. In the attack case, it is used to flood large amounts of data packets to the victim's computer in an attempt to overload it.

- $\quad$ Ping of Death:it can cripple network resources based on a flaw in the TCP/ IP. The maximum size for a packet is 65,535 bytes. If one sender were to send a packet larger than that, the receiving computer would ultimately crash from confusion.

It happens when the hackers can bypass this by cleverly sending the packets in fragments. When the fragments are assembled on the receiving computer, the overall packet size is too great, which cause the buffer overflow and crash the
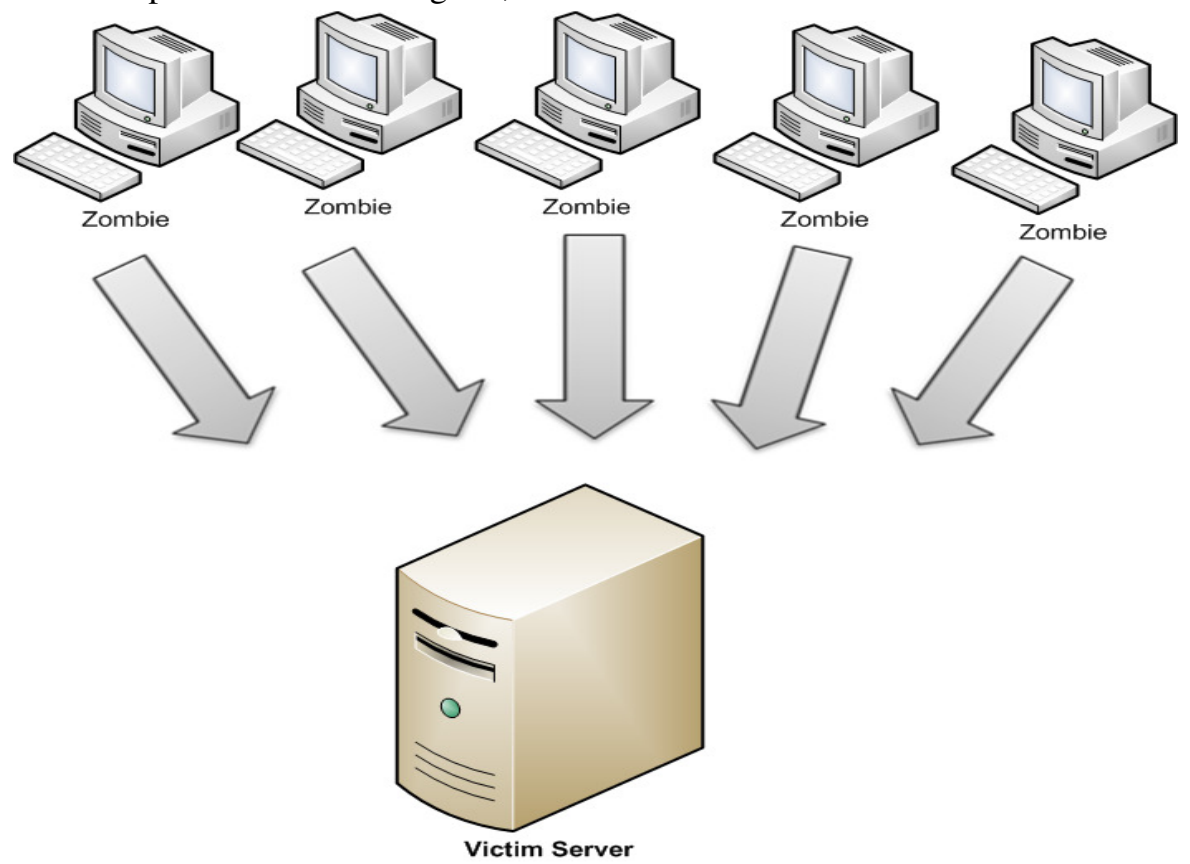

II

ial of Service (DDoS):this kind of attack is considered the worst one in denial of service attacks where multiple computers are being used. In this instance, the computers that are being used may or may not be aware of the fact that they are attacking a website or network. Trojans and viruses commonly give the attacker control of a computer. The victims of computers are called zombies. See (Fig. 2).

Figure 2. Distributed Denial of Service (DDoS) Attack

\section{IP- SPOOFING BASED TCP/IP}

IP spoofing refers to the transmission of IP packets with forged IP addresses to the victim computer. IP spoofing is most used in the internet in denial-of-service attacks. The victim computer will be flooded with useless information which overwhelms the network resources. The attacker does not wait to receive responses from the receiver of the attacked packet. The packets of this type of attack are difficult to filter since each packet appears to come from different addresses, and the source IP address of the attack is hidden. On the other hand, the 
International Journal of Distributed and Parallel Systems (IJDPS) Vol.3, No.1, January 2012

attacker aims to flood the server with such a useless packet causing the server to be shut down [11].

If a SYN request is spoofed, the victim server will never receive the final ACK packet to complete the three-way handshake.

Flooding spoofed SYN requests can easily exhaust the victim server's backlog queue, causing all the incoming SYN requests to be dropped. The stateless and destination-based nature of the Internet routing infrastructure cannot differentiate a legitimate SYN from a spoofed one, and TCP does not offer strong authentication on SYN packets [12][13].

Under IP spoofing, however, the three-way handshake will be very different from that of the normal case. Attackers usually use unreachable spoofed source IPs in the attacking packets to improve the attack efficiency [14].

\section{Previous Work on DoS Methods}

Many of the information resources that are made available and maintained inthe Internet have a high intrinsic value to their users. Their security is very important. As mentioned above, security of information resources has three components: confidentiality (protection against disclosure to unauthorized individuals); integrity (protection against alteration or corruption); and availability (protection against interference with the means to access the recourses).

Security risks are associated with allowing free access to all of the resources in an intranet or in a local area network. Many organizations adopt a firewall to make a barrier around an intranet. Nevertheless, networks are too complex to be defended using only the traditional shielding techniques of cryptography, authentication and static firewalls. Most of the security application (e.g. firewall) devices are unlikely to be able to prevent (DoS) attacks for many reasons:

A. The attacking traffic is likely to closely resemble real service requests or responses.

B. Even if they can be recognized as malicious, a successful attack is likely to produce malicious messages in such large quantities that the firewall itself is likely to be overwhelmed and become a bottleneck, preventing communication with the services that it protects [15].

Many methods have been proposed to detect the denial of SYN-Flooding attacks. A hash table is a high-performance method to detect such attack. [16] adopted a technique based on the hash table for IP traceback, which generates audit trails for the network trace so that the origin of an IP packet delivered by the network in the recent past can be traced.

A hash table has also been employed to look for imbalance between the incoming and outgoing trace packet flows to or from an IP address [17]. The flow imbalance can facilitate the detection of DoS. In normal packet flow, the number of incoming packet is matched to the number of outgoing packets over a period of time. For example, each packet in TCP connection is normally acknowledged. However, during the attacking time, the numbers of incoming and outgoing packets are imbalanced. In the case of attacking source, the number of outgoing packets exceeds the number of incoming packets. This imbalance can be used to infer that the attack is occurring. The following schemes have been presented for detecting of SYN-flooding attacks.

\section{Classification of DoS Detection SchemeS}

DoS detection schemes may be classified into three categories as shown in Fig.3: 


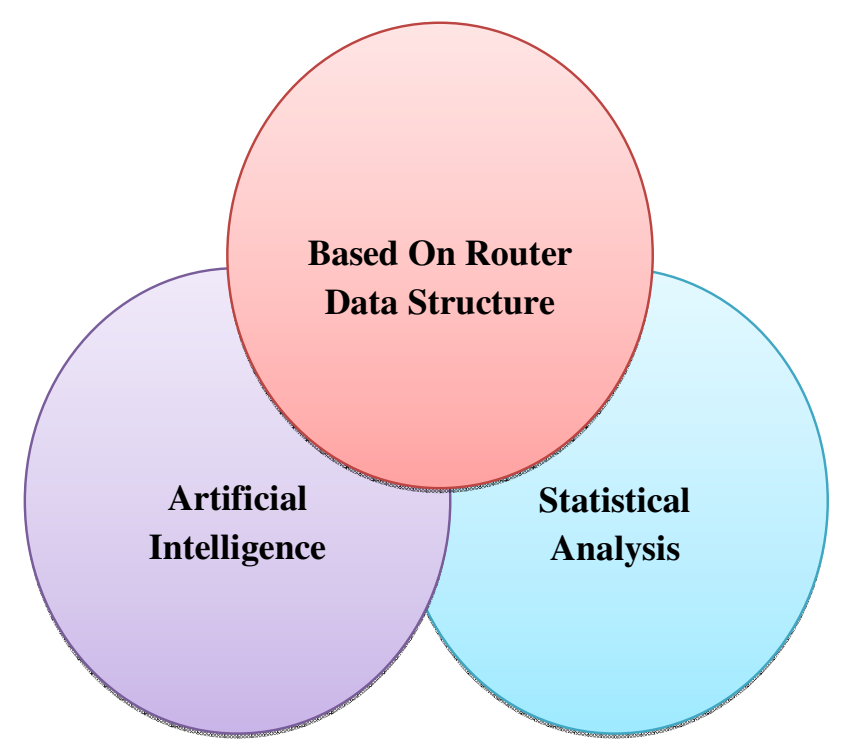

Figure 3. Denial of Service Attacks (DoS) classification schemes

7.1 Based on router data structure.

7.2 Based on statistical analysis for packet flow.

7.3 Based on Artificial Intelligence (fuzzy logic and neural network).

\subsection{Router-Based Detection Scheme using Bloom-Filter}

A bloom filter is a space-efficient data structure used in router for pattern matching in many network communications. It is used to inspect packets and detect malicious packets based on many algorithms [18],[19].

[20]focuses on the low-rate agent and present a router-based detection scheme for it. The lowrate DoS agent exploits the TCP's slow time scale of Retransmission Time Out (RTO) to reduce TCP throughput. In this case, the DoS attacker can cause a TCP flow in RTO state by sending high rate requests for short-duration bursts. Therefore, The TCP throughput at the victim side will be reduced during the attacking time on low-rate DoS agent. The proposed scheme is based on the TCP SYN-SYN/ACK protocol pairs with the consideration of packet header information (both sequence and Ack. Numbers). The Counting Bloom Filter (CBF) is used to avoid the effect of ACK retransmission, and the change point detection method is applied to avoid the dependence of detection on sites and access patterns. See (Fig.4). 


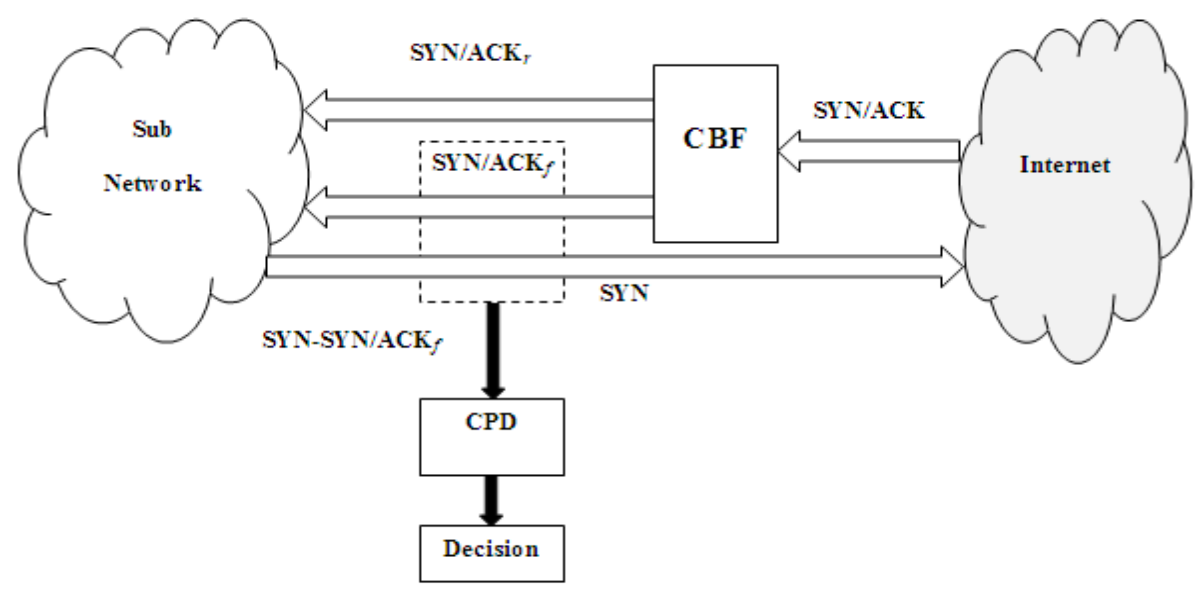

Figure 4: Router based Counter Bloom Filter (CBF) Scheme

Tracebackbased Bloom Filter (TBF) was adopted to record the TCP session statistics Internet Protocol Time To Live (IP-TTL) of SYN packets. As the attacks start, the SYN packets and IPTTL statistics were matched to differentiate the attacks' packets and record IP- TTL, because SYN-flooding attacks, are too time-expensive and consume the resources such as the memory. For instance, when SYN-flooding started, victim servers have to call for a lot of memory, usually more than $500 \mathrm{MB}$, to store the attack packets[21].

The main advantages and disadvantages for each scheme are summarized in Tables below. For the router based detection scheme, the main advantages and disadvantages of important papers are critically examined in Table 2 .

Table 2: Advantages and Disadvantages for router Scheme

\begin{tabular}{|c|l|l|l|}
\hline paper & \multicolumn{1}{|c|}{ Technique } & \multicolumn{1}{|c|}{ Disadvantages } & \multicolumn{1}{c|}{ Advantages } \\
\hline$[22]$ & $\begin{array}{l}\text { This technique adopted } \\
\text { SYN flooding detection } \\
\text { based on Bloom filter } \\
\text { (SFD-BF) in an edge } \\
\text { router to detect SYN } \\
\text { flood attack by } \\
\text { recording packet } \\
\text { information for TCP- } \\
\text { FIN pairs behaviour. }\end{array}$ & $\begin{array}{l}\text { False Positive (FP) is } \\
\text { generated due to } \\
\text { bloom filter data } \\
\text { structure. } \\
\text { This technique is } \\
\text { inefficient if in case of } \\
\text { using (FIN) in the next } \\
\text { SYN packet. }\end{array}$ & $\begin{array}{l}\text { The main advantages } \\
\text { of this technique is it } \\
\text { used the Change Point } \\
\text { Detection method } \\
\text { based on non- } \\
\text { parametric Cumulative } \\
\text { Sum (CUSUM) to } \\
\text { avoid the discrepancy } \\
\text { in small number of } \\
\text { long lived TCP and } \\
\text { retransmission of SYN } \\
\text { packets. }\end{array}$ \\
\hline$[20]$ & $\begin{array}{l}\text { This technique focuses } \\
\text { on low-rate agent, and } \\
\text { the proposed system } \\
\text { scheme is based on TCP }\end{array}$ & $\begin{array}{l}\text { All incoming SYN/ ACK } \\
\text { packets were classified } \\
\text { based on Counter Bloom } \\
\text { Filter (CBF) data }\end{array}$ & $\begin{array}{l}\text { Uses the counting bloom } \\
\text { filter data structure to } \\
\text { detect the behaviour of } \\
\text { TCP SYN-SYN/ ACK, }\end{array}$ \\
\hline
\end{tabular}




\begin{tabular}{|c|c|c|c|}
\hline & $\begin{array}{l}\text { SYN - SYN/ ACK } \\
\text { protocol pair with } \\
\text { consideration of packet } \\
\text { header information. }\end{array}$ & $\begin{array}{l}\text { structure for the sub } \\
\text { networks. If there is } \\
\text { multiple packets flow, a } \\
\text { CBF can increment and } \\
\text { cause false results in the } \\
\text { classification phase. }\end{array}$ & $\begin{array}{l}\text { and the new scheme } \\
\text { shows a shorter time to } \\
\text { both low-rate and high- } \\
\text { rate attacks. }\end{array}$ \\
\hline$[21]$ & $\begin{array}{l}\text { Records the TCP } \\
\text { session's statistics (IP- } \\
\text { TTL) of SYN packets in } \\
\text { a trace back- based } \\
\text { bloom filter. Then } \\
\text { match the SYN packets } \\
\text { and IP-TTL statistics to } \\
\text { differentiate the attack's } \\
\text { packets. }\end{array}$ & $\begin{array}{l}\text { False positive (FP) } \\
\text { results have been seen } \\
\text { when using bloom filter } \\
\text { data structure in multiple } \\
\text { packet's case. The false } \\
\text { positive occurs when the } \\
\text { detection method } \\
\text { mistakenly flags a normal } \\
\text { traffic as being attacked } \\
\text { and this way causing the } \\
\text { difficulty to measure the } \\
\text { detection accuracy. }\end{array}$ & $\begin{array}{l}\text { - Uses statistical } \\
\text { measurement to record } \\
\text { TTL from IP trace } \\
\text { back into } 256 \text { areas of } \\
\text { trace-bloom filter data } \\
\text { structure. } \\
\text { - In addition, it shows } \\
\text { efficient results when } \\
\text { packets are sent based } \\
\text { on these groups. }\end{array}$ \\
\hline$[23]$ & $\begin{array}{l}\text { This technique } \\
\text { presented } \\
\text { SYN/ACK- CliACK } \\
\text { (SACK) pair in leaf } \\
\text { router to identify } \\
\text { outgoing SYN/ACK in } \\
\text { the victim server and } \\
\text { the TCP CliACK port } \\
\text { that being attacked. The } \\
\text { SYN/ACK packet is } \\
\text { sent by the server and } \\
\text { CliACK packet is ACK } \\
\text { packet sent by the client } \\
\text { to complete the three- } \\
\text { way handshake. }\end{array}$ & $\begin{array}{l}\text { - This technique is } \\
\text { generated a False } \\
\text { Positive (FP) values } \\
\text { due to the use of } \\
\text { bloom filter data } \\
\text { structure in the case of } \\
\text { congestion status in } \\
\text { network flow } \\
\text { - This technique is } \\
\text { inefficient in the case } \\
\text { of Request- Reply } \\
\text { (RR) protocol which } \\
\text { sends the CliACK in } \\
\text { the next SYN request. }\end{array}$ & $\begin{array}{l}\text { - This technique } \\
\text { presented a quantitative } \\
\text { analysis results based on } \\
\text { Counting Bloom Filter } \\
\text { (CBF) in leaf router. } \\
\text { The CBF is used to store } \\
\text { the full information for } \\
\text { TCP connection which } \\
\text { including client and } \\
\text { server IP address, ports } \\
\text { and initial sequence } \\
\text { numbers. } \\
\text { - Low consumption of } \\
\text { memory resources. The } \\
\text { memory cost of SACK } \\
\text { technique is } 364 \text { K.B for } \\
\text { 10GBS link flow in the } \\
\text { worst case. }\end{array}$ \\
\hline [24] & $\begin{array}{l}\text { Detecting the validity of } \\
\text { outgoing SYN and } \\
\text { incoming SYN/ACK in } \\
\text { edge router is proposed. } \\
\text { The edge router } \\
\text { connects end hosts to } \\
\text { the internet. The } \\
\text { mapping process is } \\
\text { accomplished in a hash } \\
\text { map table by checking } \\
\text { pairs of outgoing SYN } \\
\text { request and incoming } \\
\text { SYN/ACK that store in } \\
\text { data base. }\end{array}$ & $\begin{array}{l}\text { - Integration process of } \\
\text { storing the packet } \\
\text { information such as } \\
\text { source and destination } \\
\text { IP addresses is } \\
\text { difficult in the case of } \\
\text { congestion in the } \\
\text { network flow. This } \\
\text { leads to incorrect } \\
\text { values in the mapping } \\
\text { table of bloom filter } \\
\text { data structure. }\end{array}$ & $\begin{array}{l}\text { - This technique } \\
\text { guarantees that each } \\
\text { packet sent by the client } \\
\text { is valid by two parts } \\
\text { which storage module } \\
\text { and inspection module. } \\
\text { - The hash table is } \\
\text { efficient to store source } \\
\text { and destination IP } \\
\text { address in the database } \\
\text { at the storage module. } \\
\text { - This technique shows an } \\
\text { accurate detection SYN } \\
\text { flood or abnormal case } \\
\text { attack based on mapping } \\
\text { table which is }\end{array}$ \\
\hline
\end{tabular}


International Journal of Distributed and Parallel Systems (IJDPS) Vol.3, No.1, January 2012

\begin{tabular}{|c|c|c|c|}
\hline & & & $\begin{array}{l}\text { constructed in the } \\
\text { storage module. }\end{array}$ \\
\hline [25] & $\begin{array}{l}\text { This paper is used to } \\
\text { examine the flooding } \\
\text { attacks against VoIP } \\
\text { architectures that } \\
\text { employ the Session } \\
\text { Initiation Protocol (SIP) } \\
\text { based on bloom filter } \\
\text { data structure in router. } \\
\text { The monitor process } \\
\text { based on bloom filter } \\
\text { combined with a new } \\
\text { metric " session } \\
\text { distance" which should } \\
\text { equal zero in normal } \\
\text { operation }\end{array}$ & $\begin{array}{l}\text { - This technique is } \\
\text { mainly increased the } \\
\text { resource consumption } \\
\text { such as CPU time and } \\
\text { memory and } \\
\text { bandwidth during the } \\
\text { DDoS flood attack } \\
\text { because it is } \\
\text { established sessions } \\
\text { between the requester } \\
\text { and responder. } \\
\text { - It is generated False } \\
\text { Positive (FP) and } \\
\text { False negative (FN) } \\
\text { values due to data } \\
\text { structure bloom filter. }\end{array}$ & $\begin{array}{l}\text { - This approach is } \\
\text { successfully reflected } \\
\text { the behaviour of } \\
\text { detection of certain } \\
\text { SYN flooding attacks in } \\
\text { Session Initiation } \\
\text { Protocol (SIP) based } \\
\text { VOIP and inefficient to } \\
\text { launches against other } \\
\text { signaling protocol } \\
\text { H.323 and MCGP. }\end{array}$ \\
\hline
\end{tabular}

\subsection{Sample Flow-Statistical Analysis}

Many efforts have been undertaken in using the sample flow of statistics to detect DoS attacks [26]-[28].

[29]presented a statistical scheme to detect the SYN-flooding accuracy on network anomalies using flow statistics obtained through packet sampling. The network anomalies generate huge number of small flows, such as network scans or SYN-flooding. Due to this reason, it is hard to detect SYN-flooding when performing packet sampling because the network flow may be either bursty (non-linear) or under the normal flow rate. Their model is based on two steps: the first step, analytical model was developed to quantitatively evaluate the effect of packet sampling on the detection accuracy and then investigated why detection accuracy worsens when the packet sampling rate decreases. In addition, it is shown that, even with a low sampling rate, the detection accuracy was increased because the monitored traffic was partitioned into groups. The results show that the proposed mechanism is demonstrated to have the capability of detecting SYN-flooding attack accurately.

According to [30], a new detection method for DoS attack traffic based on the statistical test has been adopted. Investigation of the statistics of the SYN arrival rate revealed that the SYN arrival rate can be modeled by a normal distribution. A threshold for maximum arrival rate to detect SYN-flooding traffic has been established. In addition, the threshold for incomplete three-way handshaking packet ratio to detect possible DoS traffic also has been determined. This mechanism was shown to be effective in detecting SYN-flooding attack, but for the normal traffic threshold, the value is not accurate for the whole packet flow, especially during the attacking time.

For statistical analysis, the main advantages and disadvantages of important papers are critically examined in Table 3. 
International Journal of Distributed and Parallel Systems (IJDPS) Vol.3, No.1, January 2012

Table 3: Advantages and Disadvantages for statistical analysis

\begin{tabular}{|c|c|c|c|}
\hline paper & Technique & Disadvantages & Advantages \\
\hline [29] & $\begin{array}{l}\text { An analytical model was } \\
\text { developed to } \\
\text { quantitatively evaluate } \\
\text { the effect of packet } \\
\text { sampling on the } \\
\text { detection accuracy. }\end{array}$ & $\begin{array}{l}\text { - The proposed } \\
\text { analytical model is } \\
\text { not able to detect } \\
\text { SYN-flooding when } \\
\text { the sampling rate is } \\
\text { low. } \\
\text { - In addition, the } \\
\text { statistical analysis } \\
\text { limits } \\
\text { performance of } \\
\text { network } \\
\text { communication } \\
\text { because of the } \\
\text { overhead for } \\
\text { sampling packets in } \\
\text { real time. }\end{array}$ & $\begin{array}{l}\text { Uses a threshold } \\
\text { value to detect the } \\
\text { anomalies in the flow } \\
\text { rate which is } \\
\text { determined based on } \\
\text { normal traffic } \\
\text { statistics. In addition, } \\
\text { the traffic has been } \\
\text { partitioned into } \\
\text { groups to increase the } \\
\text { detection accuracy of } \\
\text { network anomalies } \\
\text { where the low-rate } \\
\text { anomalies have been } \\
\text { detected based on } \\
\text { normal traffic } \\
\text { statistics. }\end{array}$ \\
\hline$[30]$ & $\begin{array}{l}\text { The proposed technique } \\
\text { is based on the statistical } \\
\text { test for SYN arrival rate. } \\
\text { In addition, many } \\
\text { simulation experiments } \\
\text { were used to determine } \\
\text { the threshold value for } \\
\text { traffic flow in normal } \\
\text { distribution. } \\
\text { threshold value has been } \\
\text { checked with SYN- } \\
\text { flooding threshold value } \\
\text { to detect such attack. }\end{array}$ & $\begin{array}{l}\text { There is no explicit } \\
\text { threshold value for } \\
\text { TCP SYN/ SYN- } \\
\text { ACK to determine for } \\
\text { the normal traffic and } \\
\text { difficult to determine } \\
\text { this value in low rate } \\
\text { because of false } \\
\text { positive and false- } \\
\text { negative results. } \\
\text { In addition, modelling } \\
\text { and estimation } \\
\text { network traffic is } \\
\text { difficult because the } \\
\text { network traffic has } \\
\text { linear and burst } \\
\text { characteristics. }\end{array}$ & $\begin{array}{l}\text { - The main } \\
\text { advantage of this } \\
\text { scheme is to control } \\
\text { the statistical } \\
\text { measurement under } \\
\text { the threshold value } \\
\text { in normal } \\
\text { distribution } \\
\text { simulation } \\
\text { experiments. } \\
\text { - In addition, it } \\
\text { reflects } \\
\text { behaviour } \\
\text { packet's flow and } \\
\text { how the false } \\
\text { positive and false- } \\
\text { negative values can } \\
\text { be measured. } \\
\text { Furthermore, the } \\
\text { required parameters } \\
\text { for the threshold } \\
\text { value has been } \\
\text { determined in } \\
\text { normal distribution. }\end{array}$ \\
\hline$[31]$ & $\begin{array}{l}\text { Abnormal statistics } \\
\text { method based on } \\
\text { correlation analysis is } \\
\text { developed in this } \\
\text { technique. The method is } \\
\text { based on extracting } \\
\text { anomalies space from } \\
\text { network wide traffic in }\end{array}$ & $\begin{array}{l}\text { - } \text { This technique is } \\
\text { generated very high } \\
\text { False Positive (FP) } \\
\text { results. } \\
\text { - This technique } \\
\text { might not be } \\
\text { effective if the } \\
\text { attacker is cleverly }\end{array}$ & $\begin{array}{l}\text { - This technique is } \\
\text { successfully } \\
\text { detected the DDoS } \\
\text { by monitors the } \\
\text { derivation in } \\
\text { correlation analysis } \\
\text { across network } \\
\text { traffic from normal }\end{array}$ \\
\hline
\end{tabular}


International Journal of Distributed and Parallel Systems (IJDPS) Vol.3, No.1, January 2012

\begin{tabular}{|c|c|c|c|}
\hline & the backbone network. & $\begin{array}{l}\text { send attack under } \\
\text { certain leave (low } \\
\text { rate attack) }\end{array}$ & $\begin{array}{l}\text { case. } \\
\text { - This technique } \\
\text { achieves good } \\
\text { results of detecting } \\
\text { small intensity } \\
\text { attacks compared } \\
\text { with other methods } \\
\text { such as Principle } \\
\text { Component } \\
\text { Analysis (PCA). }\end{array}$ \\
\hline$[32]$ & $\begin{array}{l}\text { Statistics method based } \\
\text { on mean to detect the } \\
\text { SYN flood attack is } \\
\text { developed in this } \\
\text { technique. The matching } \\
\text { process is conducted by } \\
\text { comparing the difference } \\
\text { between the overall } \\
\text { means analysis of } \\
\text { incoming traffic arrival } \\
\text { rate and normal traffic } \\
\text { arrival rate. }\end{array}$ & $\begin{array}{l}\text { - This technique } \\
\text { cannot overcome the } \\
\text { low-rate SYN } \\
\text { flooding attack } \\
\text { which happens on } \\
\text { condition that the } \\
\text { arrival rate } \\
\text { difference between } \\
\text { attacks and normal. } \\
\text { - False Negative (FN) } \\
\text { and False Positive } \\
\text { (FP) values are } \\
\text { generated in this } \\
\text { technique. } \\
\text { - The technique is } \\
\text { mainly included } \\
\text { resources } \\
\text { consumption in case } \\
\text { of low rate attacks } \\
\text { which leads to shut } \\
\text { down the available } \\
\text { resources. }\end{array}$ & $\begin{array}{l}\text { - The main advantage } \\
\text { of this technique is } \\
\text { low computational } \\
\text { overhead because } \\
\text { the proposed } \\
\text { scheme does not } \\
\text { hold the three-way } \\
\text { handshake states but } \\
\text { only statistically } \\
\text { analysis the SYN } \\
\text { and ACK segments. }\end{array}$ \\
\hline$[33]$ & $\begin{array}{l}\text { An Agent-based } \\
\text { Intrusion Detection } \\
\text { System (AIDS) is } \\
\text { proposed based on Chi- } \\
\text { Square statistical method } \\
\text { to detect Dos/DDoS. }\end{array}$ & $\begin{array}{l}\text { - This method is based } \\
\text { on statistics analysis } \\
\text { and does not reflect } \\
\text { the behaviour and } \\
\text { reliability of agent- } \\
\text { based Intrusion } \\
\text { Detection System } \\
\text { (AIDS). } \\
\text { The statistical } \\
\text { analysis limits the } \\
\text { performance of the } \\
\text { communication } \\
\text { because of the } \\
\text { overhead in sending } \\
\text { packets. } \\
\text { False Positive (FP) } \\
\text { values are generated } \\
\text { based on this } \\
\text { method. }\end{array}$ & $\begin{array}{l}\text {-The main advantages } \\
\text { of this method is } \\
\text { statistically analyse } \\
\text { amount and } \\
\text { variation of packet } \\
\text { issued by the } \\
\text { sender. The first } \\
\text { step in this method } \\
\text { is to find out the } \\
\text { Chi-Square and } \\
\text { after that check } \\
\text { whether or not it } \\
\text { exceeded the } \\
\text { threshold of the } \\
\text { normal distribution. }\end{array}$ \\
\hline [44] & Originalmathematical & statistical & - In this scheme, the \\
\hline
\end{tabular}




\begin{tabular}{|c|c|c|c|}
\hline & $\begin{array}{l}\text { measurements approach } \\
\text { based on entropy to } \\
\text { detect SYN-flooding } \\
\text { attacks from the victim's } \\
\text { side is proposed in this } \\
\text { technique. The technique } \\
\text { is monitored unusual } \\
\text { handshake sequences to } \\
\text { calculate the entropy. } \\
\text { This value is used to } \\
\text { detect the changes in the } \\
\text { balance of TCP } \\
\text { handshakes. }\end{array}$ & $\begin{array}{l}\text { analysis limits the } \\
\text { performance of the } \\
\text { communication } \\
\text { because of the } \\
\text { overhead. } \\
\text { - False positive (FP) } \\
\text { was generated in this } \\
\text { technique. }\end{array}$ & $\begin{array}{l}\text { accuracy detection } \\
\text { is done in real-time } \\
\text { to allow quick } \\
\text { protection and help } \\
\text { guarantee a proper } \\
\text { defense. } \\
\text { - Experimental results } \\
\text { show that the } \\
\text { method can detect } \\
\text { SYN-flooding } \\
\text { attacks with better } \\
\text { accuracy and } \\
\text { robustness methods }\end{array}$ \\
\hline$[45]$ & $\begin{array}{l}\text { - A real-time DDoS } \\
\text { attack detection and } \\
\text { prevention system } \\
\text { deployed at the leaf } \\
\text { router to monitor and } \\
\text { detect DDoS attacks was } \\
\text { proposed. } \\
\text { - The leaf router } \\
\text { respectively real timely } \\
\text { analyzes and detects the } \\
\text { clients' and servers' } \\
\text { traffic in the case of } \\
\text { SYN flooding attacks } \\
\text { and normal operations. } \\
\text { - This system } \\
\text { periodically samples the } \\
\text { traffic flow from every } \\
\text { IP address and judges } \\
\text { whether its traffic } \\
\text { behavior meets the } \\
\text { synchronization or not. }\end{array}$ & $\begin{array}{l}\text { - } \text { CPU time and } \\
\text { memory } \\
\text { consumption } \\
\text { overhead is seen in } \\
\text { this technique. }\end{array}$ & $\begin{array}{l}\text { - The main } \\
\text { advantages in this } \\
\text { technique: } \\
\text { - } \text { The system can } \\
\text { recognize } \\
\text { attackers, victims } \\
\text { and normal users, } \\
\text { and filter or } \\
\text { forward IP packets } \\
\text { by a quick } \\
\text { identification } \\
\text { technique. } \\
\text { The identification } \\
\text { technique } \\
\text { checked was } \\
\text { mismatch between } \\
\text { the request packets } \\
\text { and response } \\
\text { packets. } \\
\text { The experiment } \\
\text { results show that } \\
\text { the system can } \\
\text { make a real-time } \\
\text { detection } \\
\text { flooding attacks at } \\
\text { the early attacking } \\
\text { stage, and take } \\
\text { effective measures } \\
\text { to quench it. }\end{array}$ \\
\hline
\end{tabular}

\subsection{Detection Scheme using Fuzzy Logic and Neural Nets}

Fuzzy logic and neural network was adopted by many research to design and implement intrusion detection systems for denial of service attacks[34]-[36].

A fuzzy logic based system for detecting SYN-flooding attacks has been adopted. Fuzzy logic helps solving the systems which have elements of uncertainly. Fuzzy logic is appropriate for approaching the nonlinear systems [37]. 
[38] proposed a system represented by two blocks shown in figure 5. The first one is the packet classification block which classifies incoming network traffic packets, where the header of each captured packet is checked to see if it is a TCP SYN packet; if the fragment offset value in the header is zero, then it is a TCP packet. If the SYN flag of the flag bits in this TCP packet is one, then it is a SYN packet (attack possibility). The packet classification block collects the TCP SYN packets for a predetermined $\Delta \mathrm{t}$ time and gives them to the fuzzy logic system, which is the second block of the proposed system. The $\Delta \mathrm{t}$ in this work was 5 seconds, while the second block of the proposed system is a fuzzy logic system. This block is responsible for SYN-flooding attack detection. The detection accuracy of the proposed system was compared with Cumulative Sum (CUSUM) for five attacks and showed a high accuracy and low false-negative rate and generate an earlier alarm than CUSUM algorithm which it is an ideal algorithm for identifying DoS attacks based on the measurement for the mean in traffic before, and after they detect comparing with the threshold value.

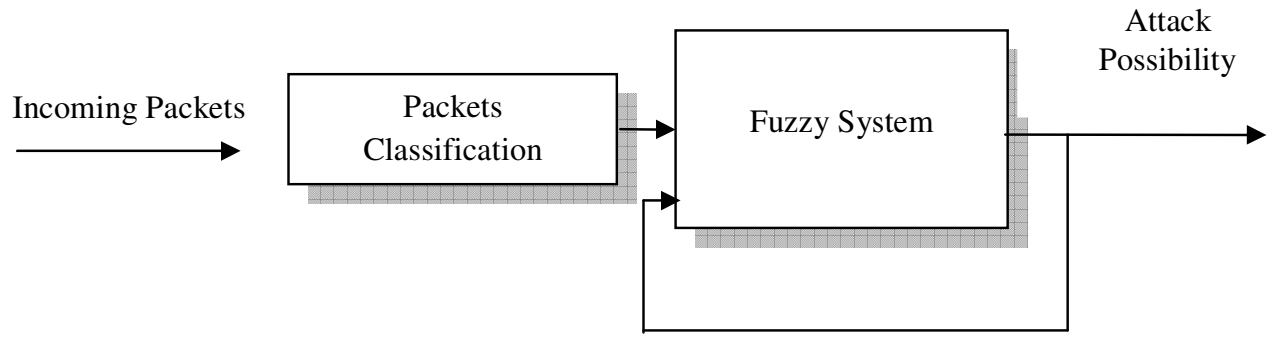

Figure 5: The proposed system based on fuzzy logic [38]

On the other hand, [39], adopted a hierarchical off-line anomaly network intrusion detection system based on Distributed Time-Delay Artificial Neural Network(DTDANN). The work aims to solve a hierarchical multi class problem in which the type of attack (DoS) detected by a dynamic neural network. Actually, the data set used by this method is old data and does not reflect the current behavior of attack packets.

For fuzzy logic and neural network detection techniques under the carter gory of artificial intelligence, the main advantages and disadvantages ofimportant papers are critically examined in Table 4:

Table 4: Advantages and Disadvantages for DoS detection based on artificial intelligence

\begin{tabular}{|c|c|c|c|}
\hline paper & Technique & Disadvantages & Advantages \\
\hline [40] & $\begin{array}{l}\text { A hybrid } \begin{array}{r}\text { Intrusion } \\
\text { Detection }\end{array} \text { System } \\
\text { based on Artificial } \\
\text { Neural Network Self- } \\
\begin{array}{l}\text { Organizing } \\
\text { (SOM) and Resilient }\end{array} \\
\text { Propagation Neural } \\
\text { Network (RPROP) is } \\
\text { proposed to detect to } \\
\text { visualize and detect } \\
\text { SYN } \\
\text { malicious. }\end{array}$ & $\begin{array}{l}\text { - Old off-line data set is } \\
\text { used from the third } \\
\text { international } \\
\text { Knowledge Discovery } \\
\text { and Data Mining } \\
\text { Tools Competition } \\
\text { (KDD Cup) since } \\
1999 \text { which is not } \\
\text { reflect the current } \\
\text { behaviour of modern } \\
\text { SYN flooding attacks. } \\
\text { - Training phase for } \\
\text { both neural network } \\
\text { are used based on }\end{array}$ & $\begin{array}{l}\text { - Quantitative } \\
\text { qualitative analysis has } \\
\text { been performed by using } \\
\text { hybrid intrusion detection } \\
\text { system based on SOM and } \\
\text { (RPROP). }\end{array}$ \\
\hline
\end{tabular}


International Journal of Distributed and Parallel Systems (IJDPS) Vol.3, No.1, January 2012

\begin{tabular}{|c|c|c|c|}
\hline & & $\begin{array}{l}\text { deterministic features } \\
\text { from the same old } \\
\text { dataset }\end{array}$ & \\
\hline [38] & $\begin{array}{l}\text { The technique uses the } \\
\text { fuzzy logic for } \\
\text { nonlinear systems to } \\
\text { detect DoS attack. }\end{array}$ & $\begin{array}{l}\text { - It is difficult to model } \\
\text { the traffic network } \\
\text { before, and after the } \\
\text { attack due to linear } \\
\text { and burst } \\
\text { characteristics of } \\
\text { packets flow. } \\
\text { - In addition, this } \\
\text { technique depends on } \\
\text { offset value in a TCP } \\
\text { packet header which } \\
\text { is a change due to } \\
\text { network congestion } \\
\text { and others states. }\end{array}$ & $\begin{array}{l}\text { This technique shows a } \\
\text { good result using a fuzzy } \\
\text { logic compared to CUSUM } \\
\text { algorithm, especially in } \\
\text { false positive and false- } \\
\text { negative measurement in } \\
\text { the low-rate flow packets. }\end{array}$ \\
\hline [39] & $\begin{array}{l}\text { This technique adopts a } \\
\text { hierarchical off-line } \\
\text { anomaly network } \\
\text { detection system based } \\
\text { on distributed time } \\
\text { delay artificial neural } \\
\text { network. }\end{array}$ & $\begin{array}{l}\text { The data set of this } \\
\text { scheme has been } \\
\text { selected from } \\
\text { DARPA intrusion } \\
\text { detection data set in } \\
1998 \text { which is does } \\
\text { not reflect the traffic } \\
\text { model in the recent } \\
\text { traffic, especially the } \\
\text { new denial of service } \\
\text { type's attacks. } \\
\text { In addition, most } \\
\text { neural network } \\
\text { requires retraining to } \\
\text { improve analysis on } \\
\text { varying input data, } \\
\text { and it is impossible } \\
\text { in an on-line traffic } \\
\text { flow. } \\
\text { In this scheme also, } \\
\text { off-line experiments } \\
\text { have been conducted } \\
\text { in neural network, } \\
\text { which is associated } \\
\text { with the } \\
\text { interconnection } \\
\text { among processing } \\
\text { elements and set of } \\
\text { desired output and } \\
\text { transfer between } \\
\text { input and output is } \\
\text { determined by } \\
\text { weights. }\end{array}$ & $\begin{array}{l}\text { The main advantages is to } \\
\text { build off-line detecting } \\
\text { system based on the } \\
\text { distribution time delay } \\
\text { artificial neural network to } \\
\text { detect multi class of denial } \\
\text { of services (DoS) attacks. }\end{array}$ \\
\hline [41] & $\begin{array}{l}\text { Alert Classification } \\
\text { System is developed by }\end{array}$ & $\begin{array}{l}\text { - Redundant alert is } \\
\text { triggered for the same }\end{array}$ & $\begin{array}{l}\text { - Many DDoS flood attacks } \\
\text { such as SYN flood TCP, }\end{array}$ \\
\hline
\end{tabular}




\begin{tabular}{|c|c|c|c|}
\hline & $\begin{array}{l}\text { using Machine } \\
\text { Learning Algorithms } \\
\text { Artificial Neural } \\
\text { Networks and Support } \\
\text { Vector Machines in } \\
\text { this technique. }\end{array}$ & $\begin{array}{l}\text { attack attributes. } \\
\text { - This technique } \\
\text { includes overhead } \\
\text { during the training } \\
\text { phase of neural } \\
\text { network and cannot } \\
\text { integrate with new } \\
\text { type of attacks. }\end{array}$ & $\begin{array}{l}\text { UDP and ICMP have been } \\
\text { detected in this based on } \\
\text { neural networks technique. } \\
\text { - This technique helps to } \\
\text { generate many DDoS } \\
\text { attacks types from real- } \\
\text { time independent network } \\
\text { which can help in } \\
\text { generalization and } \\
\text { reflecting the nature of the } \\
\text { DDoS attacks. }\end{array}$ \\
\hline [42] & $\begin{array}{l}\text { Identification the } \\
\text { occurrence of DDoS } \\
\text { intensity in real time } \\
\text { based on Fuzzy logic is } \\
\text { developed in this } \\
\text { technique }\end{array}$ & $\begin{array}{lr}\text { - } & \begin{array}{l}\text { Light or moderate } \\
\text { intensity }\end{array} \\
\text { attack is missed } \\
\text { during } \\
\text { classification phase } \\
\text { of Fuzzy logic } \\
\text { which can cause } \\
\text { more } & \text { False } \\
\text { Negative } & \text { (FN) } \\
\text { values. } & \\
\text { Difficult to set } \\
\text { Fuzzy logic during } \\
\text { DDoS attack } \\
\text { because the attacker } \\
\text { sends in nonlinear } \\
\text { way. } \\
\text { Light (low - } \\
\text { rate)DDoS flood } \\
\text { attack is not } \\
\text { detected properly in } \\
\text { this scheme. }\end{array}$ & $\begin{array}{l}\text { - The proposed method } \\
\text { adopted two hybrid } \\
\text { approaches } \\
\text { a- Statistical analysis of } \\
\text { the network traffic and } \\
\text { time series to find out } \\
\text { statistics parameters } \\
\text { that result from DDoS } \\
\text { SYN flood attack. } \\
\text { b- Determine the intensity } \\
\text { of DDoS SYN flood } \\
\text { attack by fuzzy logic. } \\
\text { The hybrid approach is } \\
\text { accurately detect the } \\
\text { DDoS SYN flood attack. }\end{array}$ \\
\hline [43] & $\begin{array}{l}\text { Multi-Layer } \\
\text { Perceptron (MLP) } \\
\text { neural network is used } \\
\text { to detect DDoS flood } \\
\text { attack. }\end{array}$ & $\begin{array}{l}\text { - False positive (FP) } \\
\text { and False negative } \\
\text { values are generated } \\
\text { in classification } \\
\text { phase of artificial } \\
\text { neural network. } \\
\text { Irrelevant neural } \\
\text { network output is } \\
\text { generated, which } \\
\text { can consider as } \\
\text { False Negative (FN) } \\
\text { values. } \\
\text { The long training } \\
\text { time of the neural } \\
\text { network was mostly } \\
\text { due to the huge } \\
\text { number of training } \\
\text { vectors } \\
\text { computation of } \\
\text { facilities. }\end{array}$ & $\begin{array}{l}\text { - This technique is slightly } \\
\text { better in classification } \\
\text { results compared with } \\
\text { other methods, where this } \\
\text { technique is more } \\
\text { computationally and } \\
\text { memory wise efficient. } \\
\text { - This technique concludes } \\
\text { that there is more to do } \\
\text { with the irrelevant output } \\
\text { in the field of artificial } \\
\text { neural network based } \\
\text { security systems. }\end{array}$ \\
\hline
\end{tabular}




\subsection{Other Detection Schemes}

There are many other detection mechanisms to detect denial of Service (DoS) apart from those mentioned above.

Data mining techniques [44]have been adopted for detection of DoS attacks in order to discover useful information and hidden relationships in large data repositories[45][46]. $\operatorname{In[46],~the~}$ network traffic and network packet protocol status model was extracted based on FCM cluster algorithms and Apriori association. The proposed system was viable in Local Area Network (LAN).[47] adopted simple proactive anti-DDoS framework. Initially DDoS attack features were analyzed. Then, variables based on these were selected by investigation many procedures. Finally, the k-nearest neighbour (K-NN), was applied to classify and detect DDoS SYN attacks for each phase. The results show that this method can classify DDoS phases correctly.

\section{Performance Measures}

In conclusion, previous researches adopted various mechanisms to detect the Denial of Service (DoS) attacks such as those based on the router data structure, statistical analysis, neural network and fuzzy logic which have their respective advantages and weakness. Nevertheless, the detection of the DoS attack is still complex. When a user sends many packets with a spoofed IP addresses, it will be difficult to model the traffic flow according to the mechanisms above as the packet flow will be in bursty (non-linear) during the attacking period. On the other hand, some users send this attack under the normal flow rate which causes difficulty in accurately diagnosing the traffic flow and detecting a DoS attack due to false positive and false negative values. As a result, a large number of pointless requests is sent, leading to the shutdown of available services.

The performance of Denial of Service (DoS) detection schemes may be measured in terms of CPU time, memory consumption, false positive and false negative detection and accuracy of detection at high rates and low rates. The performance comparison is summarized in Table 5.

Table 5.Comparison of the performance measures of each category

\begin{tabular}{|c|c|c|c|c|c|c|c|}
\hline \multirow[b]{2}{*}{$\begin{array}{c}\text { Categor } \\
\mathbf{y}\end{array}$} & \multirow[b]{2}{*}{ Papers } & \multirow[b]{2}{*}{$\begin{array}{l}\text { CPU } \\
\text { Time }\end{array}$} & \multirow[b]{2}{*}{$\begin{array}{c}\text { Memory } \\
\text { Consump } \\
\text { tion }\end{array}$} & \multirow[b]{2}{*}{$\begin{array}{c}\text { False } \\
\text { Positiv } \\
\text { e (FP) }\end{array}$} & \multirow[b]{2}{*}{$\begin{array}{l}\text { False } \\
\text { Negati } \\
\text { ve }\end{array}$} & \multicolumn{2}{|c|}{ Accuracy Detection } \\
\hline & & & & & & $\begin{array}{c}\text { Detection } \\
\text { high Rate } \\
\text { traffic }\end{array}$ & $\begin{array}{c}\text { Detection } \\
\text { Low rate } \\
\text { traffic }\end{array}$ \\
\hline \multirow{5}{*}{$\begin{array}{l}\text { Router } \\
\text { based } \\
\text { data } \\
\text { structur } \\
\text { e }\end{array}$} & [22] & flexible & flexible & high & NA & very good & no \\
\hline & [23] & flexible & flexible & high & NA & good & good \\
\hline & {$[[24]$} & flexible & flexible & high & NA & very good & fair \\
\hline & [23] & low & low & high & fair & very good & no \\
\hline & [24] & flexible & flexible & high & NA & very good & fair \\
\hline \multirow{7}{*}{$\begin{array}{l}\text { Statistic } \\
\text { al } \\
\text { Analysi } \\
\text { s }\end{array}$} & [29] & high & high & high & NA & good & no \\
\hline & [30] & high & high & high & high & good & no \\
\hline & [31] & flexible & flexible & high & NA & good & no \\
\hline & [32] & NA & NA & high & low & good & no \\
\hline & [33] & high & high & high & NA & good & no \\
\hline & [44] & high & high & high & $\mathrm{NA}$ & very good & NA \\
\hline & [45] & high & high & NA & NA & good & NA \\
\hline \multirow{3}{*}{$\begin{array}{l}\text { Artifici } \\
\text { al } \\
\text { Intellige }\end{array}$} & [40] & high & NA & NA & high & very good & NA \\
\hline & [38] & flexible & flexible & high & high & good & no \\
\hline & [39] & high & high & flexibl & NA & good & no \\
\hline
\end{tabular}


International Journal of Distributed and Parallel Systems (IJDPS) Vol.3, No.1, January 2012

\begin{tabular}{|l|c|c|c|c|c|c|c|}
\hline nce & & & & $\mathrm{e}$ & & & \\
\cline { 2 - 8 } & {$[41]$} & high & high & NA & NA & very good & no \\
\cline { 2 - 8 } & {$[42]$} & high & high & $\begin{array}{c}\text { flexibl } \\
\mathrm{e}\end{array}$ & high & good & no \\
\cline { 2 - 8 } & {$[43]$} & flexible & low & high & high & very good & no \\
\hline
\end{tabular}

\section{CONCLUSION}

In this new era of mobile computing, organizations adopt various strategies and applications to ensure the security of precious information. Intrusion detection has become an integral part of the information security process. This paper presents a summary of the state-of-the-art of detection schemes for SYN-Flooding attacks. The detection schemes for SYN- Flooding attacks have been classified broadly into three categories - detection schemes based on the router data structure, detection schemes based on statistical analysis of the packet flow and detection schemes based on artificial intelligence. The advantages and disadvantages for various detection schemes under each category have been critically examined. The performance measures of the categories have also been compared.

\section{REFERENCES}

[1] P. K. S. P. Kiran Sree, "Exploring a Novel Approach for providing Software Security Using Soft Computing Systems," International Journal of Security and Its Applications (IJSIA), vol. 2, pp. 51-58, 2008.

[2] T. M. Connolly and C. E. Begg, Database systems: Addison-Wesley : Boston, 2003.

[3] Y. Cho, et al., "Field-Programmable Logic and Applications: Reconfigurable Computing Is Going Mainstream," Field-Programmable Logic and Applications, pp. 337-357, 2002.

[4] P. Mell, et al., "Creating a Patch and Vulnerability Management Program," NIST Special Publication, vol. 800, p. 40, 2005.

[5] F. Palmieri and U. Fiore, "Network anomaly detection through nonlinear analysis," Computers \& Security, vol. 29, pp. 737-755, 2010.

[6] L. Limwiwatkul and A. Rungsawang, "Distributed denial of service detection using TCP/IP header and traffic measurement analysis," in lntanational Syinposium on Communications and Information Technologes 2004 ( ISCIT 2004 ), Japan, 2004, pp. 605-610 vol. 1.

[7] M. BoonPing Lim and S. Uddin, "Statistical-based SYN-flooding detection using programmable network processor," IEEE, vol. 3 pp. 1530-1539, 2005.

[8] H. Wang, et al., "Detecting SYN flooding attacks," IEEE, vol. 3, pp. 1530 - 1539, 2002.

[9] R. A. Shaikh, et al., "Review Over Anomaly Detection Algorithms for Detecting SYN Flooding Attacks," in Engineering Sciences and Technology, SCONEST 2005. Student Conference 2005, pp. 1-5.

[10] H. Sengar, et al., "Fast detection of denial-of-service attacks on IP telephony," in 14th IEEE International Workshop on Quality of Service. , 2006, pp. 199-208.

[11] C. Manusankar, et al., "Intrusion Detection System with Packet Filtering for IP Spoofing," in The International Conference on Communication and Computational Intelligence, India, 2010, pp. 563-567.

[12] C. L. Schuba, et al., "Analysis of a denial of service attack on TCP," in Proceedings. 1997 IEEE Symposium on Security and Privacy. Washington : DC :USA, 1997, pp. 208-223.

[13] R. K. C. Chang, "Defending against flooding-based distributed denial-of-service attacks: A tutorial," Communications Magazine, IEEE, vol. 40, pp. 42-51, 2002. 
International Journal of Distributed and Parallel Systems (IJDPS) Vol.3, No.1, January 2012

[14] D. Nashat and X. Jiang, "Detecting syn flooding agents under any type of ip spoofing," in IEEE International Conference on e-Business Engineering, 2008, pp. 499-505.

[15] R. Farrow, "Distribuited Denial of Service Attacks - how Amazon, Yahoo, eBay and others were brought down," Network Magazine April 2000.

[16] A. C. Snoeren, "Hash-based IP traceback," in In Proceedings of the ACM SIGCOMM Conference, 2001, pp. 3-14.

[17] S. Abdelsayed, et al., "An efficient filter for denial-of-service bandwidth attacks," in Global Telecommunications Conference, Australia, 2003, pp. 1353-1357 vol. 3.

[18] C. E. R. Mikko Sarela, et al., "BloomCasting: Security in Bloom filter based multicast," in Aalto University, Espoo, Finland, Finland, 2010.

[19] F. S. Tabataba and M. R. Hashemi, "Improving False Positive In Bloom Filter," IEEE, pp. 1-5, 2011.

[20] D. Nashat, et al., "Router based detection for low-rate agents of DDoS attack," in International Conference on High Performance Switching and Routing, Tohoku, 2008, pp. 177-182.

[21] H. Tang, et al., "Traceback-based Bloomfilter IPS in defending SYN flooding attack," in 5th International Conference on Wireless Communications, Networking and Mobile Computing, China, 2009, pp. 1-6.

[22] S. Changhua, Jindou, F., Lei, S., \& Bin, L., "A Novel Router-based Scheme to Mitigate SYN Flooding DDoS Attacks," in IEEE INFOCOM (Poster), Anchorage, Alaska, USA, 2007.

[23] S. Changhua, Chengchen, H., Yi, T., \& Bin, L., "More Accurate and Fast SYN Flood Detection," presented at the 18th International Conference on Computer Communications and Networks (ICCCN) San Francisco, CA, USA, 2009.

[24] L. Yun, Ye, G., \& Guiyi, W., "Detect SYN Flooding Attack in Edge Routers," International Journal of Security and Its Applications (IJSIA), vol. 3, pp. 31-45, 2009.

[25] G. Dimitris, Nikos, V., \& Costas, L., "Utilizing bloom filters for detecting flooding attacks against SIP based services," Elsevier, pp. 1-14, 2009.

[26] A. M. Neda Hantehzadeh, Vijay K. Gurbani, Lalit Gupta, Tin Kam Ho and G. Wilathgamuwa, "Statistical analysis of self-similar Session Initiation Protocol (SIP) messages for anomaly detection," in Sixth International Conference on Intelligent Information Hiding and Multimedia Signal Processing (IIH-MSP), Germany, 2010, pp. 704 - 707.

[27] C. James and H. A. Murthy, "Time Series Models and its Relevance to Modeling TCP SYN Based DoS Attacks," in Next Generation Internet, Kaiserslautern, Germany, 2011, pp. 1-8.

[28] J. Y. Lifang Zi, Xin-Wen Wuz, "Adaptive Clustering with Feature Ranking for DDoS Attacks Detection " in 7th EURO-NGI on Next Generation Internet (NGI), Germany, 2011, pp. 1 - 8

[29] R. Kawahara, et al., "Detection accuracy of network anomalies using sampled flow statistics," International Journal of Network Management, pp. 1959-1964, 2007.

[30] C. L. Chen, "Detecting distributed denial-of-service attack traffic by statistical test," in Third International Conference on Communications and Networking, China, 2008, pp. 1253-1257.

[31] L. Zong-Lin, Guang-Min, H., \& Dan, Y., "Global abnormal correlation analysis for DDoS attack detection," in IEEE Symposium on Computers and Communications( ISCC), Marrakech, 2008, pp. $310-315$.

[32] C. Chin-Ling, " A New Detection Method for Distributed Denial-of-Service Attack Traffic based on Statistical Test," Journal of Universal Computer Science, vol. 15, pp. 488-503., 2009.

[33] L. Fang-Yie, \& Chia-Chi, P., "Detecting DoS and DDoS Attacks using Chi-Square," in Fifth International Conference on Information Assurance and Security (IAS), Xian, 2009, pp. 255 258. 
International Journal of Distributed and Parallel Systems (IJDPS) Vol.3, No.1, January 2012

[34] M. Yanchun, "System for attack recognition based on mining fuzzy association rules," in International Conforence On Computer Design And Appliations, China 2010, pp. 129 -133

[35] C.-L. Tsai, et al., "Early Warning System for DDoS Attacking Based on Multilayer Deployment of Time Delay Neural Network," in Sixth International Conference on Intelligent Information Hiding and Multimedia Signal Processing, Darmstadt ; Germany, 2010, pp. 704 - 707.

[36] J. Li, et al., "DDoS Attack Detection Based On Neural Network," in 2nd International Symposium on Aware Computing, Taiwan, 2010, pp. 196 - 199.

[37] L. A. Zadeh, "Fuzzy sets," Information and control, vol. 8, pp. 338-353, 1965.

[38] T. Tuncer and Y. Tatar, "Detection SYN Flooding Attacks Using Fuzzy Logic," in International Conference on Information Security and Assurance, 2008, pp. 321-325.

[39] L. M. Ibrahim, "Anomly Network Intrusion Detection System Based On Distributed Time-Delay Neural Network (DTDNN)," Journal of Engineering Science and Technology, vol. 5, pp. 457471, 2010.

[40] C. Jirapummin, Wattanapongsakorn, N., \& Kanthamanon, P. , "Hybrid Neural Networks for Intrusion Detection System," Institute of Electronics, Information and Communication Engineers (IEICE), pp. 1-4, 2002.

[41] T. Subbulakshmi, Mercy Shalinie, S., \& Ramamoorthi, A., "Detection and Classification of DDoS Attacks Using Machine Learning Algorithms," European Journal of Scientific Research, vol. 47, pp. 334-346, 2010.

[42] Z. Xia, Lu, S., Li, J., \& Tang, J., "Enhancing DDoS Flood Attack Detection via Intelligent Fuzzy Logic," Informatica (Slovenia), pp. 497-507, 2010.

[43] M. Norouzian, \& Merati, S. , "Classifying Attacks in a Network Intrusion Detection System Based on Artificial Neural Networks," in 13th International Conference on Advanced Communication Technology (ICACT), Korea, 2011, pp. 868 - 873.

[44] P.-N. Tan, Steinbach, M., \& Kumar, V., Introduction to data Mining: New York: AddisonWesley, 2005.

[45] G. Kanwal, \& Rshma, C. , "Detection of DDoS Attacks Using Data Mining," International Journal of Computing and Business Research (IJCBR), vol. 2, pp. 1-10., 2011.

[46] Z. Rui, \& Guangxue, Y., "DDoS Detection System Based on Data Mining," in the Second International Symposium on Networking and Network Security (ISNNS '10) Jinggangshan, P. R. China, 2010 pp. 62-65.

[47] N. Hoai-Vu, \& Yongsun, C., "Proactive Detection of DDoS Attacks Utilizing k-NN Classifier in an Anti-DDos Framework. ," in the International Journal of Electrical and Electronics Engineering 247-252, 2010

\section{Authors}

Mehdi EbadyManaa is currentlypursuing his Master of Science at University Utara Malaysia. He will graduate in 2012. His Bachelor of Science is from University of Babylon in Iraq. His main area of research is network security. He is currently focusingon the detection of SYN-flooding attacks in Local Area Networks.

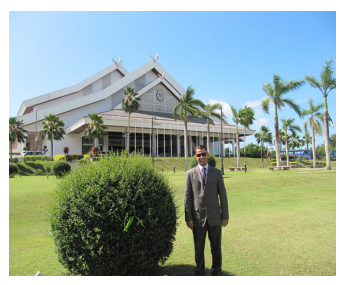

Dr. Angela Amphawanreceived her Ph.D. degree from University of Oxford, United Kingdom. In her doctoral research, she successfully increased the bandwidth of a multimode fiber channel using a novel holographic selective launch. Her research interests include radio and optical communication technologies. 